\title{
A Novel Elongational Rheology Control of PS by SBS and Dicumyl Peroxide
}

\author{
Akinari MINEGISHI, Akihiro NISHIOKA, Tatsuhiro TAKAHASHI, \\ Yuichi MASUBUCHI, Jun-ichi TAKIMOTO, and Kiyohito KOYAMA* \\ Department of Polymer Science and Engineering, \\ Yamagata University, Yonezawa 992-8510, Japan \\ (Received : January 13, 2005)
}

\begin{abstract}
A novel polystyrene(PS) with an incorporation of a small mass fraction of styrene-butadine-styrene(SBS) and dicumyl peroxide(DCP) has been developed to enhance strain-hardening significantly under elongational flow. Here, strain-hardening is defined as steep increase of elongational viscosity at large strain which deviates from linear viscoelastic curve. The content of SBS was in a range from $1 \mathrm{wt} \%$ to $10 \mathrm{wt} \%$, and the content of DCP was in a range from $0.01 \mathrm{wt} \%$ to $0.1 \mathrm{wt} \%$. Pure PS at $180{ }^{\circ} \mathrm{C}$ did not exhibit any strain-hardening. Whereas, significant enhancement of strain-hardening was observed for PS blended only $1 \mathrm{wt} \%$ SBS and $0.1 \mathrm{wt} \%$ DCP. The magnitude of strain-hardening (SH) was over 10 up to Hencky strain of 3 . Note that the parameter, $\mathrm{SH}$, is defined as elongational viscosity at large strain to linear viscoelastic envelope at the same time. Enhancement of strain-hardening was in the order of SBS content and DCP content. The magnitude of strain-hardening(SH) for PS/SBS/DCP(SH 70 at the maximum) was much more remarkable than that of any other PS such as PS/UHMW-PS and branched PS reported before $(\mathrm{SH}<10)$. This is a new method to control elongational rheology of PS and has advantages over conventional ways in terms of its easier process than other methods such as introducing long-chain branching and high molecular weight in postreactor.
\end{abstract}

Key Words: Uniaxial elongational viscosity / Strain-hardening / Polystyrene / Styren-butadiene-styrene block copolymer / Dicumyl peroxide

\section{INTRODUCTION}

Elongational flow is one of the dominant flow in polymer processing. The presence of strain-hardening(steep increase of elongational viscosity at large strain which deviates from linear viscoelastic curve) under elongational flow is one of the most important properties for processability of blow molding, extrusion foaming, film blowing, fiber spinning etc. Extensive studies about elongational rheology indicate that strainhardening is sensitive to molecular weight distribution and long-chain branching. ${ }^{1-12)}$ In recent years, the introduction of a small mass fraction of extremely high molecular weight component into normal molecular weight polymer has been attractive and noticeable because of its effective method of strain-hardening enhancement., ${ }^{2-12)}$ Takahashi et al. reported that effect of high molecular weight component and miscibility on strain-hardening. ${ }^{11)}$ The enhancement of strain-hardening was observed for Polymethylmethacrylate(PMMA)/UltraHigh-Molecular Weight(UHMW)-PMMA(98.5/1.5) in

* To whom correspondence should be addressed.

TEL. +81-(0)238-26-3055, FAX. +81-(0)238-26-3411, E-mail: koyama@yz.yamagata-u.ac.jp homogeneous blend and Acrylonitrile-Styrene(AS)/UHMWPMMA(98.5/1.5) in miscible blends. Minegishi et al. reported elongational flow behavior of a series of Polystyrene(PS)/ ultrahigh molecular weight(UHMW)-PS. ${ }^{12)}$ The enhancement of strain-hardening is observed only when the content of high molecular weight component reaches and exceeds the critical concentration of entanglement. Sugimoto et al. reported uniaxial and biaxial elongational flow behavior of Polypropylene(PP) introduced UHMW-Polyethylene(PE) in postreactor. ${ }^{13)}$ The magnitude of strain-hardening( $\mathrm{SH})$ for all samples above mentioned was approximately $10(\mathrm{SH} \sim 10)$. Note that the parameter, $\mathrm{SH}$, is defined as elongational viscosity at large strain to linear viscoelastic envelope at the same time.

On the other hand, few studies have been reported about decrease of strain-hardening or strain-softening. Utracki et al. reported uniaxial elongational flow behavior of a series of PS/ Low-density-Polyethylene(LDPE) blends with and without compatibilizer, SEB (hydrogenated poly(styrene-bisoprene)). ${ }^{14)}$ By incorporating 5wt $\%$ SEB in PS/LDPE blends, unexpected decrease of strain-hardening and increase of linear viscoelastic envelope(LVE) were observed. A similar finding 
was reported for PP/Styrene-Butadiene-Styrene-tri-block-copolymer(SBS)/Stylene-Maleic-Anhydride(SMA)(65/20/15 $\mathrm{wt} \%$ ) blend. ${ }^{15)}$ It is conjectured that this is related to flow properties of SBS triblock copolymer melts since it shows strain-softening under uniaxial elongational flow. ${ }^{16)}$

Taking these things into account, existence of SBS in matrix polymer will make strain-hardening weaker. However, elongational flow behavior of PS/SBS was not changed by adding SBS. Furthermore, PS/SBS/Dicumyl Peroxide(DCP) blends showed large enhancement of strain-hardening as compared with PS matrix, and value of SH reached approximately 70 at the maximum. This novel elongational rheology has not been observed for any other $\operatorname{PS}(\mathrm{SH}<10)$ before. $^{2,5,8,12)}$ Thus, we have found a novel elongational rheology utilizing a PS by SBS and DCP which enable us to control elongational rheology by a small mass fraction of component. A test measurement in uniaxial elongation for a series of PSs with changing SBS content and DCP content was conducted. The results are presented in this article.

\section{EXPERIMENTAL}

Polystyrene (PS666, $M_{\mathrm{w}}=220 \mathrm{k}, M_{\mathrm{w}} / M_{\mathrm{n}}=2.0$ ) which was kindly supplied from A\&M styrene Co. Ltd., styrenebutadiene-styrene(SBS) triblock copolymer(SBS, $M_{\mathrm{w}}=80 \mathrm{k}$, $M_{\mathrm{w}} / M_{\mathrm{n}}=1.3, \mathrm{~S} / \mathrm{B} / \mathrm{S}=20 / 60 / 20$, lamella structure) and dicumyl peroxide(DCP, Nippon Oil Fat Co. Ltd., half-reduction period: $1 \mathrm{~s}$ at $180^{\circ} \mathrm{C}$ ) were used. To make the mixture of PS, SBS and DCP, two samples were dissolved in tetrahydorofluen (THF) to make a $5 \mathrm{wt} \%$ solution. Then the solution was dried at room temperature and further dried at $120^{\circ} \mathrm{C}$ under vacuum for $48 \mathrm{~h}$. This preparation method of sample has already been established. ${ }^{17)}$ The sample was heated under $10 \mathrm{MPa}$ at $180{ }^{\circ} \mathrm{C}$ for $20 \mathrm{~min}$ to obtain cross-linking reaction and cooled rapidly. Again, the sample was heated to $140{ }^{\circ} \mathrm{C}$ and cooled gradually below $T_{\mathrm{g}}$ to prevent shrink during uniaxial elongational measurement. Each sample was dried under vacuum at $80{ }^{\circ} \mathrm{C}$ for $24 \mathrm{~h}$ to eliminate water.

The transient growth of uniaxial elongational viscosity was measured on thin slabs of material by using new Meissner type elongational rheometer(RME, Rheometics). A detailed description and discussion of reliability of the elongational rheometer were given by Meissner and Hostettler. ${ }^{18)}$ This device provides a constant elongational rate to a sample by gripping it between counter-rotating caterpillar tracks. The sample was both heated and suspended mechanically over a rising current of temperature-controlled nitrogen. Measurement temperatures were $140{ }^{\circ} \mathrm{C}$ and $180^{\circ} \mathrm{C}$. The strain rates were $0.5,0.2,0.1,0.05,0.02$ and $0.01 \mathrm{~s}^{-1}$, and uniformity of the sample was carefully checked by direct video imaging. The data caused by non-uniformity of the sample, apparent slipping of sample between counter-rotating caterpillar tracks, and lower limitation of elongational force were discarded.

\section{RESULTS AND DISCUSSION}

Figure 1(a) shows time-dependent uniaxial elongational viscosity of PS666 at $180^{\circ} \mathrm{C}$. No strain-hardening(SH 1) was observed below the strain rate of $0.1 \mathrm{~s}^{-1}$. Figure $1(\mathrm{~b})$ shows timedependent uniaxial elongational viscosity of SBS at $180{ }^{\circ} \mathrm{C}$. SBS showed weak strain-softening. Due to too low viscosity of SBS, the measurement was carried out at $140^{\circ} \mathrm{C}$. Takahashi et al. reported that the same pure SBS at $180^{\circ} \mathrm{C}$ showed weak strain-softening under uniaxial elongational flow. ${ }^{16)}$

Figures 2(a) (d) show time-dependent uniaxial elongational viscosity of PS666/SBS(90/10) with various content of DCP in the range from 0 to $0.1 \mathrm{wt} \%$. Elongational flow behavior of PS666/SBS(90/10)andPS666/SBS(90/10, peroxide=0.01wt $\%$ ) was quite similar to that of PS666. However, PS666/SBS(90/ 10 , peroxide $=0.05 \mathrm{wt} \%$ ) showed totally different behavior. Strain-hardening was pronounced over a wide range of strain rates. The magnitude of strain-hardening $(\mathrm{SH})$ almost reached 10 and did not tend to reach steady state. Furthermore, for

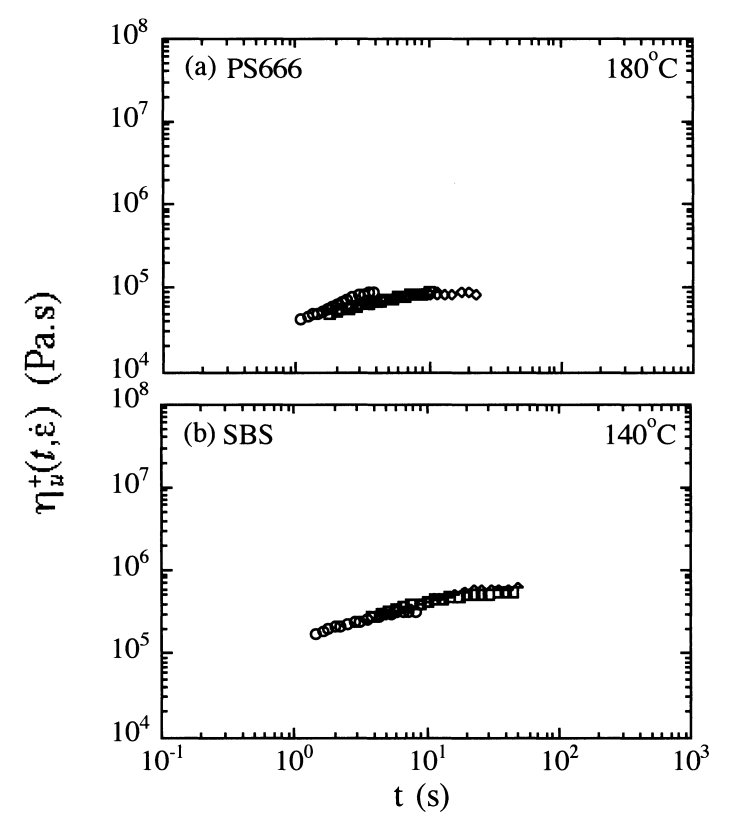

Fig. 1a, b Time-dependent uniaxial elongational viscosity of PS666 at $180{ }^{\circ} \mathrm{C}$ and SBS at $140{ }^{\circ} \mathrm{C}$ under various constant strain rates $\left(\mathrm{s}^{-1}\right)$ : a for PS666 $(\bigcirc) 0.5 ;(\square) 0.2 ;(\triangle) 0.1 ;(\diamond) 0.05 ; \mathbf{b}$ for SBS $(\bigcirc) 0.2$; $(\square) 0.05 ;(\triangle) 0.02$. 
PS666/SBS(90/10, peroxide $=0.1 \mathrm{wt} \%$ ), the enhancement of strain-hardening was much more pronounced than that of PS666/SBS(90/10, peroxide=0.05wt $\%$ ). The magnitude of strain-hardening(SH) reached 30 40 at higher strain rates and reached approximately 70 at lower strain rates. This novel enhancement has never been observed for any other PS $(\mathrm{SH}<10)$ yet.

The effect of SBS content on elongational rheology was investigated. The amount of DCP was fixed at $0.1 \mathrm{wt} \%$.
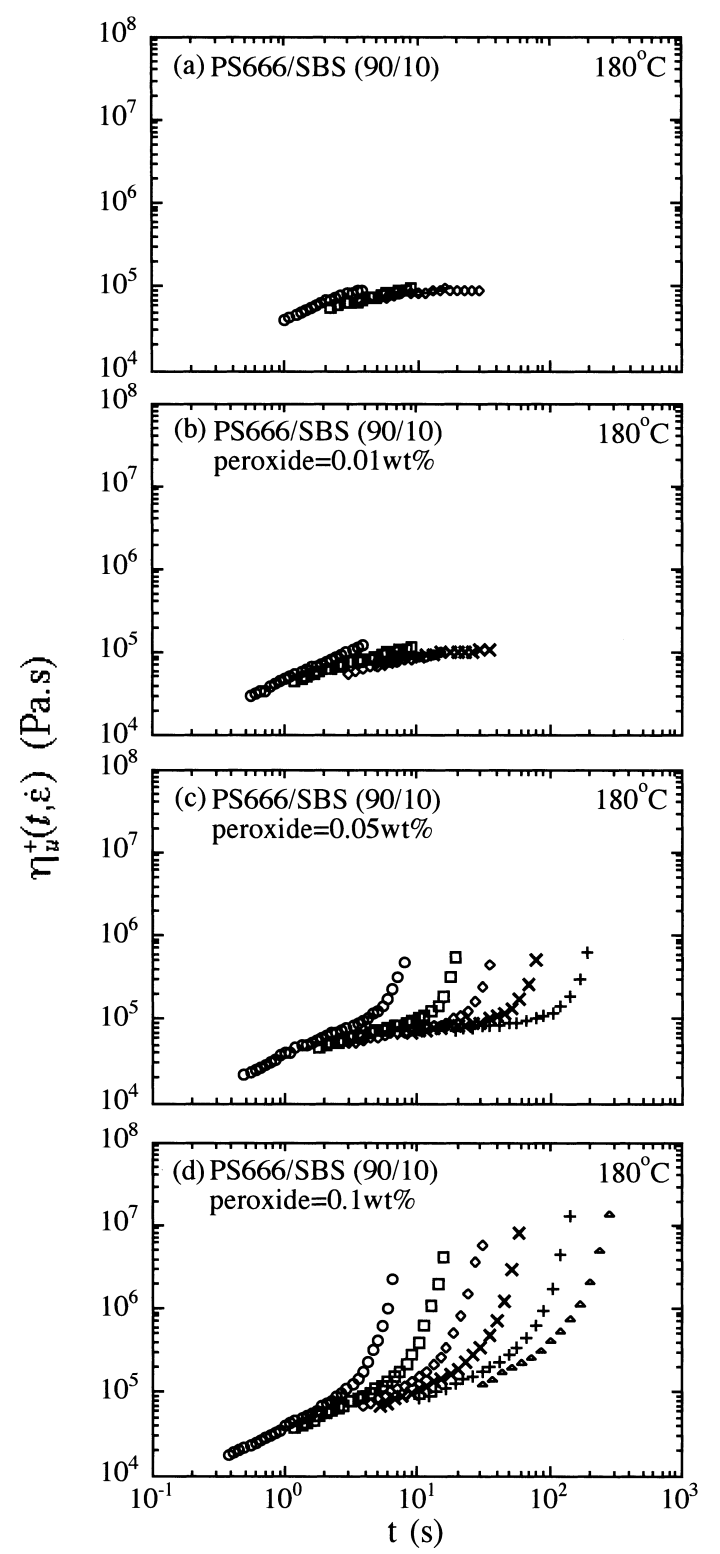

Fig. 2a-d Time-dependent uniaxial elongational viscosity of PS666/SBS blends modified by dicumyl peroxide at $180^{\circ} \mathrm{C}$ under various constant strain rates $\left(\mathrm{s}^{-1}\right)$ : a for PS666/SBS $(90 / 10)(\mathrm{O}) 0.5$; $(\square) 0.2 ;(\triangle) 0.1 ;(\diamond) 0.05 ; \mathbf{b}$ for PS666/SBS $(90 / 10$, peroxide $=$ $0.01 \mathrm{wt} \%)(\mathrm{O}) 0.5 ;(\square) 0.2 ;(\diamond) 0.1 ;(\times) 0.05 ; \mathbf{c}$ for PS666/ SBS $(90 / 10$, peroxide $=0.05 \mathrm{wt} \%)(\mathrm{O}) 0.5 ;(\square) 0.2 ;(\diamond) 0.1 ;(\times) 0.05$; $(+) 0.02 ; \mathbf{d}$ for PS666/SBS( $(90 / 10$, peroxide $=0.1 \mathrm{wt} \%)(O) 0.5$; $(\square) 0.2 ;(\diamond) 0.1 ;(\times) 0.05 ;(+) 0.02 ;(\triangle) 0.01$.
Figure 3(a) shows time-dependent uniaxial elongational viscosity of PS666/SBS(95/5, peroxide $=0.1 \mathrm{wt} \%$ ) and PS666/ $\operatorname{SBS}(99 / 1$, peroxide $=0.1 \mathrm{wt} \%)$ at $180^{\circ} \mathrm{C}$. For both samples, enhancement of strain-hardening was in the order of SBS content and the magnitude( $\mathrm{SH}$ ) reached approximately 5 30 according to strain rates.

Uniaxial elongational flow behavior of PS666 blended DCP was almost the same as that of PS666, which suggested that PS chains were not influenced by DCP. Whereas, PS666/SBS modified DCP exhibited enhancement of strain-hardening. This is in harmony with the picture of PS/SBS treated at high temperature. ${ }^{19)}$ This novel enhancement of PS/SBS/DCP would result from significant stretch of SBS component generated by crosslinking reaction between butadiene in SBS and DCP. Futher details of this novel enhancement of strainhardening in uniaxial elongational regimes will be investigated in our future work.

\section{CONCLUSION}

In this paper, we have found a novel elongational rheology utilizing a PS by SBS and DCP, being enable us to control elongational rheology by a small mass fraction of component. The magnitude of strain-hardening $(\mathrm{SH})$ for PS/SBS/DCP

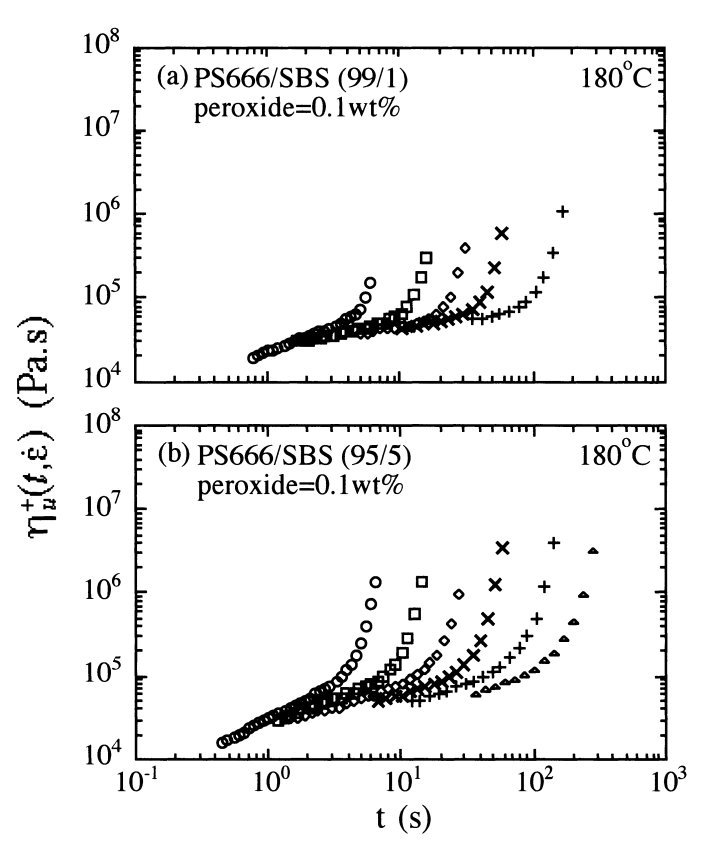

Fig. 3a, b Time-dependent uniaxial elongational viscosity of PS666/SBS blends modified by dicumyl peroxide at $180{ }^{\circ} \mathrm{C}$ under various constant strain rates $\left(\mathrm{s}^{-1}\right)$ : a for $\operatorname{PS} 666 / \mathrm{SBS}(99 / 1$, peroxide $=$ $0.1 \mathrm{wt} \%)(\mathrm{O}) 0.5 ;(\square) 0.2 ;(\diamond) 0.1 ;(\times) 0.05 ;(+) 0.02$; b for PS666/ $\operatorname{SBS}(95 / 5$, peroxide $=0.1 \mathrm{wt} \%)(\bigcirc) 0.5 ;(\square) 0.2 ;(\diamond) 0.1 ;(\times) 0.05$; $(+) 0.02 ;(\triangle) 0.01$. 
blend was much more remarkable than that of any other PS such as PS/UHMW-PS and branched PS reported before. This results mean that this is one of the new methods to control intensity of strain hardening for PS and has advantages over conventional ways in terms of its easier process than other methods such as introducing long-chain branching and high molecular component and so on.

\section{Acknowledgements}

We are grateful to Asahi chemical Co. Ltd for providing samples and helpful discussions. The authors would also like to thank Prof. Dr. K. Osaki (Kyoto University, Japan) for his valuable comments and suggestions. This work financially supported by Research Fellowships of the Japanese Society for the Promotion of Science.(No. 15300250).

\section{REFERENCES}

1) Ide Y, White JL, J Appl Polym Sci, 22, 1061 (1978).

2) Münstedt H, J Rheol, 24, 847 (1980).

3) Ishizuka O, Koyama K, Polymer, 21, 164 (1980).

4) Schlund B, Utracki LA, Polym Eng Sci, 27, 1523 (1987).

5) Li L, Masuda T, Takahashi M, Ohno H, Nihon Reoroji Gakkaishi (J Soc Rheol, Jpn), 16, 117 (1988).
6) Berger L, Meissner J, Rheol Acta, 31, 63 (1992).

7) Hingmann R, Marczinke BL, J Rheol, 38, 573 (1994).

8) Ebrahimi NG, Takahashi M, Araki O, Masuda T, J Rheol, 39, 1385 (1995).

9) Minegishi A, Naka Y, Takahashi T, Masubuchi Y, Takimoto J, Koyama K, Nihon Reoroji Gakkaishi (J Soc Rheol, Jpn), 25, 215 (1997).

10) Okamoto M, Kojima A, Kotaka T, Polymer, 39, 2149 (1998).

11) Takahashi T, Takimoto J, Koyama K, J Appl Polym Sci, 72, 961 (1999).

12) Minegishi $M$, Nishioka A, Takahashi T, Masubuchi $Y$, Takimoto J, Koyama K, Rheol Acta, 40, 329 (2001).

13) Sugimoto $M$, Masubuchi $Y$, Takimoto J, Koyama K, Macromolecules, 34, 6056 (2001).

14) Utracki LA, Sammut P, Polym Eng Sci, 30, 1019 (1990).

15) Tanaka K, Koyama K, Watanabe J, Seni-Gakkaishi, 50, 1, (1994).

16) Takahashi T, Takimoto J, Koyama K, Mat Sci Res Int, 4, 97 (1998).

17) Takahashi T, Takimoto J, Koyama K, J Appl Polym Sci, 73, 757 (1999).

18) Meissner J, Hostettler J, Rheol Acta, 33, 1 (1994).

19) Minegishi A, Tatsuhiro T, Nishioka A, Masubuchi Y, Takimoto $\mathrm{J}$, Koyama K, in preparation. 